\title{
Use of onabotulinum toxin A in patients with idiopathic overactive bladder and a lack of efficacy, intolerance or contraindication with anticholinergics
}

\section{Uso de la onabotulinumtoxina A en pacientes con vejiga hiperactiva idiopática con falta de eficacia, intolerancia o contraindicación para los anticolinérgicos}

\author{
Irma Amparo Ospina-Galeano ${ }^{1}$ José Medina-Polo ${ }^{1}$ Susana de la Rosa-Kerhmann ${ }^{1}$ \\ Felipe Villacampa-Aubá ${ }^{1}$ Felix Guerrero-Ramos ${ }^{1}$ Juan Bautista Passas-Martínez ${ }^{1}$ \\ 1 Departamento de Urología, Hospital Universitario 12 de Octubre, \\ Address for correspondence Irma Amparo Ospina-Galeano, \\ Madrid, Spain \\ Departamento de Urología, Hospital Universitario 12 de Octubre, \\ Madrid, Spain (e-mail: irmaospinagaleano@gmail.com).
}

Urol Colomb 2018;27:86-91.

\begin{abstract}
Objective To assess the efficacy and safety of onabotulinum toxin A in patients with idiopathic overactive bladder inadequately managed with anticholinergics.

Materials and Methods A prospective, open-label, single centre, and interventional study was conducted, from 2008 to 2013, on consecutive patients with idiophatic overactive bladder that showed lack of efficacy or intolerance to anticholinergic agents. Results The study included 73 female patients aged $58.9 \pm 12.9$ years. A dose of 100 and 200 units of toxin were administered in 89 and 5 cases, respectively. Nineteen patients received a second injection, 8 patients received 3 , and one patient was treated 4 times. Clinically, it was observed that $98 \%$ patients had urge urinary incontinence at baseline, as compared with $42 \%$ under treatment. Similar results were obtained

\section{Keywords}

- onabotulinum toxin A

- idiopathic overactive bladder

- urinary incontinence

- involuntary detrusor contraction

- urodynamic parameters

- anticholinergics regarding the number of pads used per day, from 2.8 at baseline to 0.5 after treatment as regards the urodynamic parameters, the first desire to void volume improved from $97 \pm 63 \mathrm{~mL}$ to $139 \pm 81 \mathrm{~mL}$. Similar results were obtained as regards cystometric capacity and the volume of the first involuntary detrusor contraction. One patient had a positive urine culture resolved using a conventional oral antibiotic regimen. Intermittent catheterisation was required in 5 patients during the first week.

Conclusions Onabotulinum toxin A injections significantly improved, not only the clinical symptoms, but also the urodynamic parameters in patients with idiopathic overactive bladder inadequately managed with anticholinergic drugs. This is a simple technique with minimal adverse effects and generally well tolerated.
\end{abstract}

received

February 12, 2015

accepted

October 26, 2015

published online

January 10, 2018
DOI https://doi.org/

10.1016/j.uroco.2015.10.010.

ISSN 0120-789X.

eISSN 2027-0119.
Copyright $\odot 2018$, Sociedad Colombiana License terms de Urología. Publicado por Thieme Revinter Publicações Ltda., Rio de Janeiro, Brazil. Todos los derechos reservados.

(ㄷ) (i) $\ni$ (5) 


\section{Resumen}

\section{Palabras-Clave}

- onabotulinumtoxina A

- vejiga hiperactiva idiopática

- incontinencia urinaria

- contracción involuntaria del detrusor

- parámetros urodinámicos

- anticolinérgicos
Objetivo Evaluar la eficacia y seguridad de onabotulinumtoxina A en pacientes con vejiga hiperactiva idiopática con falta de eficacia, intolerancia o contraindicación para el uso de anticolinérgicos.

Material and Métodos Se realizó un estudio observacional, prospectivo, abierto en un único centro entre 2008 y 2013, en pacientes consecutivos con vejiga hiperactiva idiopática con falta de eficacia o intolerancia a los anticolinérgicos.

Resultados Las 73 pacientes fueron mujeres con edad de 58,9 $\pm 12,9$ años. Se administraron 100 y 200 unidades de toxina en 89 y 5 casos, respectivamente. Diecinueve pacientes recibieron una segunda inyección, 8 pacientes 3 inyecciones y un paciente 4 . Clínicamente se observó que inicialmente un $98 \%$ de las pacientes tenían incontinencia urinaria de urgencia y después del tratamiento solo un $42 \%$; el número de absorbentes por día, pasó de 2,8 al inicio a 0,5 después del tratamiento. Respecto a los parámetros urodinámicos, el volumen del primer deseo miccional mejoró de $97 \pm 63$ $\mathrm{mL}$ a $139 \pm 81 \mathrm{~mL}$. Se obtuvieron resultados similares en capacidad cistométrica y el volumen de la primera contracción involuntaria del detrusor. Una paciente tuvo urocultivo positivo, resolviéndose con un régimen de antibiótico oral convencional. El cateterismo intermitente fue necesario en 5 pacientes durante la primera semana. Conclusiones Las inyecciones de onabotulinumtoxina A mejoraron significativamente no solo los síntomas clínicos, sino también los parámetros urodinámicos en pacientes con vejiga hiperactiva idiopática inadecuadamente manejados con anticolinérgicos. Esta es una técnica simple, con efectos adversos mínimos y generalmente bien tolerada.

\section{Introduction}

The International Continent Society (ICS) defines overactive bladder $(\mathrm{OAB})$ as a syndrome characterized by lower urinary tract symptoms, such as urgency with or without urge urinary incontinence, and is usually accompanied by urinary frequency and nocturia. ${ }^{1}$

$\mathrm{OAB}$ has an overall prevalence that ranges from $12 \%$ to $19 \%$ and its presence imposes a huge burden on the healthcare system, society, and quality of life of affected individuals. ${ }^{2}$ In urology, the use of Onabotulinumtoxin A has been widely evaluated in neurogenic overactive bladder patients. ${ }^{3-9}$ Additionally, different studies supported its use in $\mathrm{OAB}$ patients with persistent urge urinary incontinence, showing improvement in patients' quality of life and in some urodynamic parameters. ${ }^{10,11}$

According to the European Association of Urology (EAU) and American Urological Association (AUA) guidelines, first line therapy includes rehabilitation and pharmacologic treatment with antimuscarinic agents and 33 -adrenergic receptor agonists. ${ }^{12-14}$ When patients are either intolerant or refractory to the pharmacological treatment, both botulinum toxin applications as well as sacral neuromodulation are the recommended alternatives. $^{15}$ In a retrospective study Makovey et al $^{16}$ reported successful outcomes following onabotulinumtoxin $\mathrm{A}$ injections in $34 / 57$ (60\%) patients treated secondary to lack of anticholinergic efficacy and in 24/28 (86\%) due to intolerable side effects. There is increasing evidence suggesting that botulinum toxin treatment was associated with less urinary symptoms and an improvement in the patient's quality of life. ${ }^{17}$
There is currently a level of evidence A for the use of onabotulinumtoxin $\mathrm{A}$ in patients with idiopathic overactive bladder inadequately managed with anticholinergics. ${ }^{18}$

The purpose of this study was to assess the urodynamic parameters and adverse events in patients with idiopathic overactive bladder, inadequately managed with anticholinergics, treated with onabotulinumtoxin A.

\section{Material and Methods}

A prospective, open-label, public single center, and observational study was conducted, from 2008 to 2013, on consecutive patients with idiopathic overactive bladder (IOAB) that shown either lack of efficacy or intolerance to anticholinergic agents. Patients received treatment with either100 and 200 units of onabotulinumtoxin A (BOTOX® Allergan, Inc., Irvine, CA) according to the patient needs.

Patients with IOAB symptoms that did not respond to anticholinergic treatment were referred to the Specialty Urology Femenine and Functional Unit of our hospital where they performed a comprehensive study. All participants were required to meet the following inclusion criteria: age equal or greater than 18 years and idiopathic overactive bladder refractory to anticholinergic medications. Patients with a clinical diagnosed other than IOAB (i.e. neurogenic bladder or interstitial cystitis), any condition considered to be a contraindication to botulinum toxin treatment (allergic reaction, diseases of the neuromuscular junction, peripheral neuropathic diseases, etc.), neoplasms, anatomical changes, and pregnancy or lactation were excluded of the analysis. 
The study protocol was approved by the local ethics committee. All patients were fully informed about the details of the study protocol and patients provided written informed consent. The ethical principles outlined in the Declaration of Helsinki and Good Clinical Practice were followed.

Baseline examination included medical history, a 3-day voiding diary, assessment of quality of life (OAB-q-SF), post void residual, treatment assessment, urine culture, and urodynamic studies before and after that onabotulinumtoxin A had been administered. Follow-up visits were scheduled at week 1 , month 2 , month 6 , month 9 , month 12 , and thereafter, every 6 months during the length of follow-up (-Table 1).

Onabotulinumtoxin A was injected into the detrusor muscle at 20 injecting sites, avoiding the trigone, by using a cystoscope and flexible cystoscopic injection needle under intravenous sedation in outpatient surgery center. Antibiotic prophylaxis with intravenous cefazolin $(2 \mathrm{~g})$ was used; in those cases with allergy to cefazolin, vancomycin was used. Onabotulinumtoxin A injections contained a preparation of 100 units diluted with $10 \mathrm{~mL} 0.9 \%$ saline. $0.5 \mathrm{~mL}$ were injected in each point with a gap between them of approximately 1 centimeter. Once administered botulinum toxin and after checking that there have been no adverse effects, such as hematuria and assess that the patient urinates properly, the patient is sent home without bladder catheter but with an antibiotic treatment for 3-7 days. One week after that botulinum toxin has been administered the patient returns to the Hospital to perform a clinical assessment, measurement of the post void residual urine volume and rule out the presence of urinary tract infections. According to the protocol used in our Hospital is recommended rule out urinary infection both before and after administration of botulinum toxin.

Indication of self-catheterization depended of the post void residual urine volume and symptoms. The self- catheterization was usually indicated in those patients with post void residual urine volume greater than $200 \mathrm{~mL}$ and/or with symptoms. This study evaluated the number of patients requiring catheterization after administration of botulinum toxin and the duration thereof. During the follow-up of the patients, a worsening as for the clinical parameters they were had in account for the reinjection of the toxin.

Health related quality of life (HRQoL) was assessed by using the Overactive Bladder Questionnaire Short Form (OAB-q SF) Symptom Severity translated and validated in
Spanish. The OAB-q SF consists of a 6-item symptom-bother scale and a 13-item HRQoL scale. The HRQoL scale is divided into three subscales: coping (5 items), sleep (3 items), and emotional social ( 5 items). The results were evaluated by calculating the average score for each of the sections of the questionnaire, symptoms and quality of life, respectively.

\section{Statiscal Analysis}

A standard statistical analysis was performed using SPSS 15.0 (SPSS Inc. Chicago, IL, USA). Descriptive statistics [mean (standard deviation)] were used to report demographic and clinical characteristics. As data were normally distributed, the twotailed paired-samples Student's t-test was used to compare means between baseline and post onabotulinumtoxin A injection for quantitative variables. Categorical variables were compared using a Chi-square test. In case that all urodynamic parameters data were not collected for one or more patients, the missing values were replaced with a geometric mean. Comparisons between pre-intervention and post-intervention values were performed for urge urinary incontinence (Incontinence or not with the urgency), nighttime urinary frequency (NUF, number of micturitions at night), daytime urinary frequency (DUF, To tolerate or not mas of $2 \mathrm{~h}$ without urinating), and number of sanitary napkin per day. Additionally, the differences between baseline and post onabotulinumtoxin $\mathrm{A}$ injection values were assessed for the different urodynamic parameters (Volume at first involuntary detrusor contraction, maximum cystometric capacity, maximum detrusor pressure, post void residual, and first desire to void volume). A P value of less than 0.05 was considered significant.

\section{Results}

63 patients fulfilled the respective demands of the inclusion and exclusion criteria. All patients were women with a mean age of $58.9 \pm 12.9$ years. The measurement of the American Society of Anaesthesiologist (ASA) risk assessment scale shown 13 (14\%) patients classified as ASA I, 62 (66\%) as ASA II, and 19 (20\%) as ASA III, respectively (-Table 2).

Among the 73 patients included in the study, additional injections were required in 28 (30\%) of them, of whom 19 (20\%) received onabotulinumtoxin A twice, 8(9\%) were treated three times, and 1 patient received four treatment sessions.

Tabla 1 Scheduled follow-up visits and data collection

\begin{tabular}{|l|l|l|l|l|l|l|l|}
\hline & Baseline & Week 1 & Month 2 & Month 6 & Month 9 & Month 12 & $\begin{array}{l}\text { Every 6 months } \\
\text { thereafter }\end{array}$ \\
\hline Medical history & $\mathrm{X}$ & & & & & & \\
\hline Voiding diary & $\mathrm{X}$ & $\mathrm{X}$ & $\mathrm{X}$ & $\mathrm{X}$ & $\mathrm{X}$ & $\mathrm{X}$ & $\mathrm{X}$ \\
\hline Quality of life & $\mathrm{X}$ & & $\mathrm{X}$ & & & $\mathrm{X}$ & $\mathrm{X}$ \\
\hline Anticholinergic & $\mathrm{X}$ & & $\mathrm{X}$ & $\mathrm{X}$ & $\mathrm{X}$ & $\mathrm{X}$ & $\mathrm{X}$ \\
\hline Post void residual & $\mathrm{X}$ & $\mathrm{X}$ & $\mathrm{X}$ & & & $\mathrm{X}$ & $\mathrm{X}$ \\
\hline Urine culture & $\mathrm{X}$ & $\mathrm{X}$ & & & & & \\
\hline Urodynamic study & $\mathrm{X}$ & & & $\mathrm{X}$ & & $\mathrm{X}$ & $\mathrm{X}$ \\
\hline
\end{tabular}


Tabla 2 Baseline demographic characteristics

\begin{tabular}{|l|l|}
\hline Characteristics & Number of patients \\
\hline \multirow{3}{*}{ Sex } & Female: $73(100 \%)$ \\
\cline { 2 - 2 } & Male: $0(0 \%)$ \\
\hline \multirow{2}{*}{ SSA $^{\text {a }}$} & I: $13(14 \%)$ \\
\cline { 2 - 2 } & II: $62(66 \%)$ \\
\cline { 2 - 2 } & III: $19(20 \%)$ \\
\hline Age (years) & $58.9 \pm 12.9$ \\
\hline Anticholinergic medication & $40(85 \%)$ \\
\hline
\end{tabular}

${ }^{\mathrm{a}}$ American Society of Anaesthesiologist Risk Assessment Scale.

Regarding the onabotulinumtoxin A doses administered in our study, 100 units were used in 89 procedures, 200 units were administered in 5 procedures. Among those patients requiring additional onabotulinumtoxin $A$ treatments, the mean time between injections were $22 \pm 7$ months between the first and the second dose, $17 \pm 10$ months between the second and the third treatment, and $20 \pm 6$ months between the third and the fourth session.

At baseline 92 (98\%) patients had urge urinary incontinence as compared with 39 (42\%) under onabotulinumtoxin A treatment, $p<0.0001$ ( - Table 3). Similar results were obtained regarding the number of sanitary pads per day, from $2.8 \pm 1.8$ at baseline to $0.5 \pm 0.8$ after treatment, $p<0.0001$. Additionally, the nighttime urinary frequency significantly decreased from $3 \pm 1.5$ at baseline to $1.5 \pm 1.0$ under onabotulinumtoxin A treatment, $p<0.0001$ ( - Table 3).
Regarding the urodynamic parameters, the first desire to void volume significantly improved from $97 \pm 63 \mathrm{~mL}$ to $139 \pm 81 \mathrm{~mL}$ under treatment with onabotulinumtoxin $\mathrm{A}$, $p=0.001$. Similar results were obtained regarding maximum cystometric capacity and volume at first involuntary detrusor contraction, $p=0.001$ and $p=0.007$, respectively ( - Table 4).

Finally, as regards the adverse effects, one patient had a positive urine culture that was successfully resolved with a conventional oral antibiotic regimen. Intermittent catheterization was necessary in 5 patients during the first week after botulinum toxin administration and no patient needed clean intermittent catheterization after three months. In this study, no patient had hematuria or pain after injection.

Although the protocol included the assessment of quality of life, many patients did not complete the questionnaire. This fact has caused that the information concerning HRQoL was not included in the analysis.

\section{Discussion}

The results of this study suggest that treatment with onabotulinumtoxin A resulted in significant improvements in urodynamic parameters in patients with idiopathic overactive bladder inadequately managed with anticholinergics.

Botulinumtoxin A in the urinary tract was first described by Dykstra et al. in 1988, who injected it into the external urinary sphincter to treat detrusor sphincter dyssynergia in patients with spinal cord injury.3 Subsequently, Schurch et al. in 2000 evaluated the use of onabotulinumtoxin A for the treatment of neurogenic detrusor overactivity in 12 patients with spinal cord injury.7 Additionally, Giannantoni

Tabla 3 Overview of the values of clinical variables of the study subjects pre- and post-botulinum toxin injection

\begin{tabular}{|l|l|l|l|l|}
\hline Number of patients (\%) & Baseline & $\begin{array}{l}\text { Onabotulinum } \\
\text { toxin A }\end{array}$ & $\begin{array}{l}\text { Difference between } \\
\text { pre and post (\%) }\end{array}$ & $P$ value \\
\hline Episodes of urge urinary incontinence & $92(98 \%)$ & $39(42 \%)$ & $56 \%$ & $<0.0001$ \\
\hline Urgency & $30(64 \%)$ & $11(23 \%)$ & $41 \%$ & 0.0001 \\
\hline Daytime urinary frequency $>$ 2h & $6(12 \%)$ & $28(60 \%)$ & $48 \%$ & $<0.0001$ \\
\hline Nighttime urinary frequency (hours) & $3.0 \pm 1.5$ & $1.5 \pm 0.8$ & $50 \%$ & $<0.0001$ \\
\hline Number of pads per day & $2.8 \pm 1.8$ & $0.5 \pm 0.8$ & $82 \%$ & $<0.0001$ \\
\hline
\end{tabular}

Tabla 4 A comparison of the urodynamic parameters of the study population pre- and post-onabotulinumtoxin A injection

\begin{tabular}{|l|l|l|l|l|}
\hline Urodynamic parameters & Baseline & $\begin{array}{l}\text { Onabotulinum } \\
\text { toxin A }\end{array}$ & Difference & $P$ value \\
\hline First desire to void volume $(\mathrm{mL})$ & $97 \pm 63$ & $139 \pm 81$ & $42 \mathrm{~mL}(17.4 \%)$ & $0.001^{*}$ \\
\hline $\begin{array}{l}\text { Volume at first involuntary } \\
\text { detrusor contraction }(\mathrm{mL})\end{array}$ & $99 \pm 58$ & $158 \pm 95$ & $59 \mathrm{~mL}(16.2 \%)$ & $0.007^{*}$ \\
\hline Maximum cystometric capacity $(\mathrm{mL})$ & $206 \pm 104$ & $303 \pm 111$ & $97 \mathrm{~mL}(22.2 \%)$ & $0.001^{*}$ \\
\hline Maximum detrusor pressure $\left(\mathrm{cmH}_{2} \mathrm{O}\right)$ & $27 \pm 13$ & $23 \pm 23$ & $-4.0 \mathrm{~mL}(3.9 \%)$ & 0.302 \\
\hline Post void residual $(\mathrm{mL})$ & $15 \pm 32$ & $23 \pm 52$ & $8 \mathrm{~mL}(8.9 \%)$ & 0.357 \\
\hline
\end{tabular}

${ }^{*} P$-values were considered statistically significant at $<0.05$. 
et al. published the first controlled study of onabotulinumtoxin $\mathrm{A}$ in patients with neurogenic detrusor overactivity. ${ }^{19}$

Cruz et al. evaluated the effects of onabotulinumtoxin A on urinary incontinence, urodynamic parameters, and quality of life in incontinent patients with neurogenic overactive bladder, finding a significant improvement in all of them. ${ }^{20}$

Our study in focus in patients with $O A B$ in which there had been verified the intolerance or lack of efficiency of anticholinergics, the results of our study also agree with those published by Nitti et al. that evaluated the efficacy and safety of onabotulinumtoxin $A$ in patients with $O A B$ and urinary incontinence inadequately managed with anticholinergics. ${ }^{21}$

Moreover, the improvement of the urodynamic parameters found in our study agreed with other studies published up to the date. ${ }^{11,22-25}$ Denys et al. reported a significant improvement of the volume at first involuntary detrusor contraction after treatment with 100 units of onabotulinumtoxin $A$, that in our case with $42 \mathrm{mLI}$ reach a statistically significant difference, $P=0.007 .{ }^{11}$ Additionally Schmid et al. reported an increase of the mean volume at first desire to void increased from 126 to $212 \mathrm{~mL}^{22}$ Similarly, our study found a significant increase in this urodynamic parameter $(p=0.001)$. Dowson et al. reported a significant increase in the maximum cystometric capacity in patients with bladder oversensitivity treated with 100 units of onabotulinumtoxin A. ${ }^{24}$ In agreement with this study we found a significant increase in the maximum cystometric capacity of $97 \pm 113 \mathrm{~mL}, p<0.001$.

We find the mean time to need for retreatment was 20 months in those 19 patients that required a second dose and 17 months in those 8 ones that needed a third session of treatment and 20 months who received four treatment sessions. The mean time to need for retreatment found in our study is slightly higher than that reported by Brubaker et al, ${ }^{26}$ who reported 370 days. Urinary retention, which is displayed as one of the potential side effects after intravesical injections of botulinum toxin, can lead to the need for intermittent catheterization. Although we noted an increase in mean post void residual from baseline to the last follow-up visit of $8 \mathrm{~mL}$, it was not statistically significant $(p=0.357)$. Our results are in line with those previous reports. $2,10,23$

Furthermore, intermittent catheterization was necessary in 5 (5.3\%) patients during the first week after botulinum toxin administration and no patient needed clean intermittent catheterization for three months. According to the literature the need of catheterization ranges from 10 to $43 \% .{ }^{26}$ The volume recommended for doing a catheterization is not currently defined, although it is often done with symptomatic post void residual volumes above $200 \mathrm{~mL}$ or when it is greater than the $40 \%$ of the void volume. ${ }^{2}$ As regards the health related quality of life, the results of the OAB-q SF found in our study suggested a significant improvement in HRQoL in those patients treated with onabotulinumtoxin A. As previously mentioned in the result section, many patients did not complete the questionnaire. Nevertheless, in those patients that completed it the results agreed with those previously published Chapple et $\mathrm{al}^{2}$ who reported significant improvements in HRQoL with onabotulinumtoxin A compared with placebo.
We should recognize that there are some limitations in this study, such as referral bias or its open-label design. The lack of standard features of clinical trials such as placebo controls, randomization, and blinding of raters are all inherent limitations of open-label studies. Nevertheless, the fact that the data analysis was conducted in a masked fashion may have reduced the potential for bias. Probably the most important limitation is the lack of information about the parameters of quality of life. Although the assessment of quality of life was planned in the protocol, many patients did not answer the questionnaire. Therefore we have not been able to perform an analysis of the quality of life. Other limitation is this study is that is a single center study. Nevertheless, the fact of including a large number of patients minimizes the impact of such limitation.

\section{Conclusions}

Onabotulinumtoxin A injections significantly improved not only the clinical symptoms but also the urodynamic parameters in patients with idiopathic overactive bladder inadequately managed with anticholinergics. This is a simple technique with minimal adverse effects and generally well tolerated. Further investigations are needed to concentrate on perfecting injection parameters, such as number, volume, and depth of injections.

\section{Ethical Responsibilities}

\section{Protection of people and animals}

The authors declare that this research has not been conducted experiments on humans or animals.

\section{Confidentiality of data}

The authors declare that this article does not appear patient data.

\section{Right to privacy and informed consent}

The authors declare that this article does not appear patient data.

\section{Conflict of interest}

The authors declare no conflict of interest.

\section{Acknowledgements}

Mercedes Cano, nurse of the Functional Urology Unit at the Hospital Universitario 12 de Octubre, for her assistance in the protocol and the urodynamic studies.

\section{References}

1 Abrams FP, Cardozo FL, Fall FM, et al. The standardisation of terminology of lower urinary tract function: report from the Standardisation Sub-committee of the International Continence Society. Neurourol Urodyn 2002;21:167-178

2 Chapple FC, Sievert FK, MacDiarmid FS, et al. OnabotulinumtoxinA $100 \mathrm{U}$ significantly improves all idiopathic overactive bladder symptoms and quality of life in patients with overactive bladder 
and urinary incontinence: a randomised, double-blind, placebocontrolled trial. Eur Urol 2013;64:249-256

3 Dykstra FD, Sidi FA, Scott FA, Pagel FJ, Goldish FG. Effects of botulinum A toxin on detrusor-sphincter dyssynergia in spinal cord injury patients. J Urol 1988;139:919-922

4 Schurch FB, Hodler FJ, Rodic FB. Botulinum A toxin as a treatment of detrusorsphincter dyssynergia in patients with spinal cord injury: MRI controlled transperineal injections. J Neurol Neurosurg Psychiatry 1997;63:474-476

5 Dykstra FD, Sidi FA. Treatment of detrusor-sphincter dyssynergia with botulinum A toxin: a double-blind study. Arch Phys Med Rehabil 1990;71:24-26

6 Petit FH, Wiart FL, Gaujard FE, et al. Botulinum A toxin treatment for detrusor-sphincter dyssynergia in spinal cord disease. Spinal Cord 1998;36:91-94

7 Schurch FB, Schmid FD, Stohrer FM. Treatment of neurogenic incontinence with botulinum toxin A. N Engl J Med 2000;342:665

8 de Seze FM, Petit FH, Gallien FP, et al. Botulinum a toxin and detrusor sphincter dyssynergia: a double-blind lidocaine-controlled study in 13 patients with spinal cord disease. Eur Urol 2002;42:56-62

9 Reitz FA, Stohrer FM, Kramer FG, et al. European experience of 200 cases treated with botulinum-A toxin injections into the detrusor muscle for urinary incontinence due to neurogenic detrusor overactivity. Eur Urol 2004;45:510-515

10 Dmochowski FR, Chapple FC, Nitti FV, et al. Efficacy and safety of onabotulinumtoxinA for idiopathic overactive bladder: a doubleblind, placebo controlled, randomized, dose ranging trial. J Urol 2010;184:2416-2422

11 Denys FP, Le Normand FL, Ghout FI, et al. Efficacy and safety of low doses of onabotulinumtoxinA for the treatment of refractory idiopathic overactive bladder: a multicentre, double-blind, randomised, placebo-controlled dose-ranging study. Eur Urol 2012; 61:520-529

12 Stöhrer FM, Blok FB, Castro-Diaz FD, et al. EAU guidelines on neurogenic lower urinary tract dysfunction. Eur Urol 2009;56:81-88

13 Gormley FE, Lightner FD, Burgio FK, et al. Diagnosis and treatment of overactive bladder (non-neurogenic) in adults: AUA/SUFU guideline. J Urol 2012;188:2455-2463

14 Lucas FM, Bosch FR, Burkhard FF, et al. European Association of Urology guidelines on assessment and nonsurgical management of urinary incontinence. Actas Urol Esp 2013;37:199-213
15 Schulte-Baukloh FH. Botulinum toxin (BoNT): short form of a European consensus panel report regarding recommendations on the use of botulinum toxin in the treatment of lower urinary tract disorders and pelvic floor dysfunctions. Urol Ausg A 2010;49:56-63

16 Makovey FI, Davis FT, Guralnick FM, O'Connor FR. Botulinum toxin outcomes for idiopathic overactive bladder stratified by indication: lack of anticholinergic efficacy versus intolerability. Neurourol Urodyn 2011;30:1538-1540

17 Cui FY, Wang FL, Liu FL, et al. Botulinum toxin-A injections for idiopathic overactive bladder: a systematic review and metaanalysis. Urol Int 2013;91:429-438

18 Robinson FD, Cardozo FL. Overactive bladder: diagnosis and management. Maturitas 2012;71:188-193

19 Giannantoni FA, Di Stasi FS, Stephen FR, Bini FV, Costantini FE, Porena FM. Intravesical resiniferatoxin versus botulinum-A toxin injections for neurogenic detrusor overactivity: a prospective randomized study. J Urol 2004;172:240-243

20 Cruz FF, Herschorn FS, Aliotta FP, et al. Efficacy and safety of onabotulinumtoxinA in patients with urinary incontinence due to neurogenic detrusor overactivity: a randomised, double-blind, placebo-controlled trial. Eur Urol 2011;60:742-750

21 Nitti FV, Dmochowski FR, Herschorn FS, et al. Haag-Molkenteller: OnabotulinumtoxinA for the treatment of patients with overactive bladder and urinary incontinence: results of a phase 3 , randomized, placebo controlled trial. J Urol 2013;89:2186-2193

22 Schmid FD, Sauermann FP, Werner FM, et al. Experience with 100 cases treated with botulinum-A toxin injections in the detrusor muscle for idiopathic overactive bladder syndrome refractory to anticholinergics. J Urol 2006;176:177-185

23 Duthie FJ, Vicent FM, Herbison FG, Wilson FD, Wilson FD. Botulinum toxin injections for adults with overactive bladder syndrome. CDS Rev 2011:CD005493

24 Dowson FC, Sahai FA, Watkins FJ, Dasgupta FP, Khan FM. The safety and efficacy of botulinum toxin-A in the management of bladder oversensitivity: a randomized double-blind placebo-controlled trial. Int J Clin Pract 2011;65:698-704

25 Yokoyama FT, Chancellor FM, Oguma FK, et al. Botulinum toxin type A for the treatment of lower urinary tract disorders. Int J Urol 2012;19:202-215

26 Brubaker FL, Gousse FA, Sand FP, et al. Treatment satisfaction and goal attainment with onabotulinumtoxinA in patients with incontinence due to idiopathic OAB. Int Urogynecol J 2012;23:1017-1025 